\title{
Short Fourth Metacarpal Bone in Sickle Cell Anemia
}

\author{
Mohammad Bagherzadeh ${ }^{1}$; Mahmoud Parham ${ }^{1, *}$ \\ ${ }^{1}$ Clinical Research Development Center, Qom University of Medical Sciences, Qom, IR Iran \\ *Corresponding author: Mahmoud Parham, Clinical Research Development Center, Qom University of Medical Sciences, Qom, IR Iran. E-mail: drparham@muq.ac.ir
}

Received: May 20, 2014; Accepted: July 5, 2014

A 19-year-old man referred to the emergency department with generalized extremity pain. He had past medical history of sickle cell anemia. On physical examination, body temperature was normal and short right fourth-metacarpal bone was observed, but there was no sign of genetic disorders like turner syndrome, McCune-Albright, and hypothyroidism. Laboratory tests including thyroid function, calcium, phosphorus, and alkaline phosphatase were normal. On radiologic study, right fourth-metacarpal bone was short (Figure $1 \mathrm{~A})$. Peripheral blood smear showed sickle cell bodies (Figure 1
B). Short metacarpal bone has been reported in psuodohypoparathyroidism, turner syndrome, rheumatoid arthritis, and ankylosing spondylitis, but this deformity was observed in sickle cell anemia. Repeated painful vaso-occlusive crises are common in sickle cell anemia [1]. These crises lead to infarcts, necrosis and degenerative changes in marrow-containing bone and most commonly involve long bones, but it can affect any bone [2]. His symptoms resolved after 3 days treatment with hydration and analgesic.

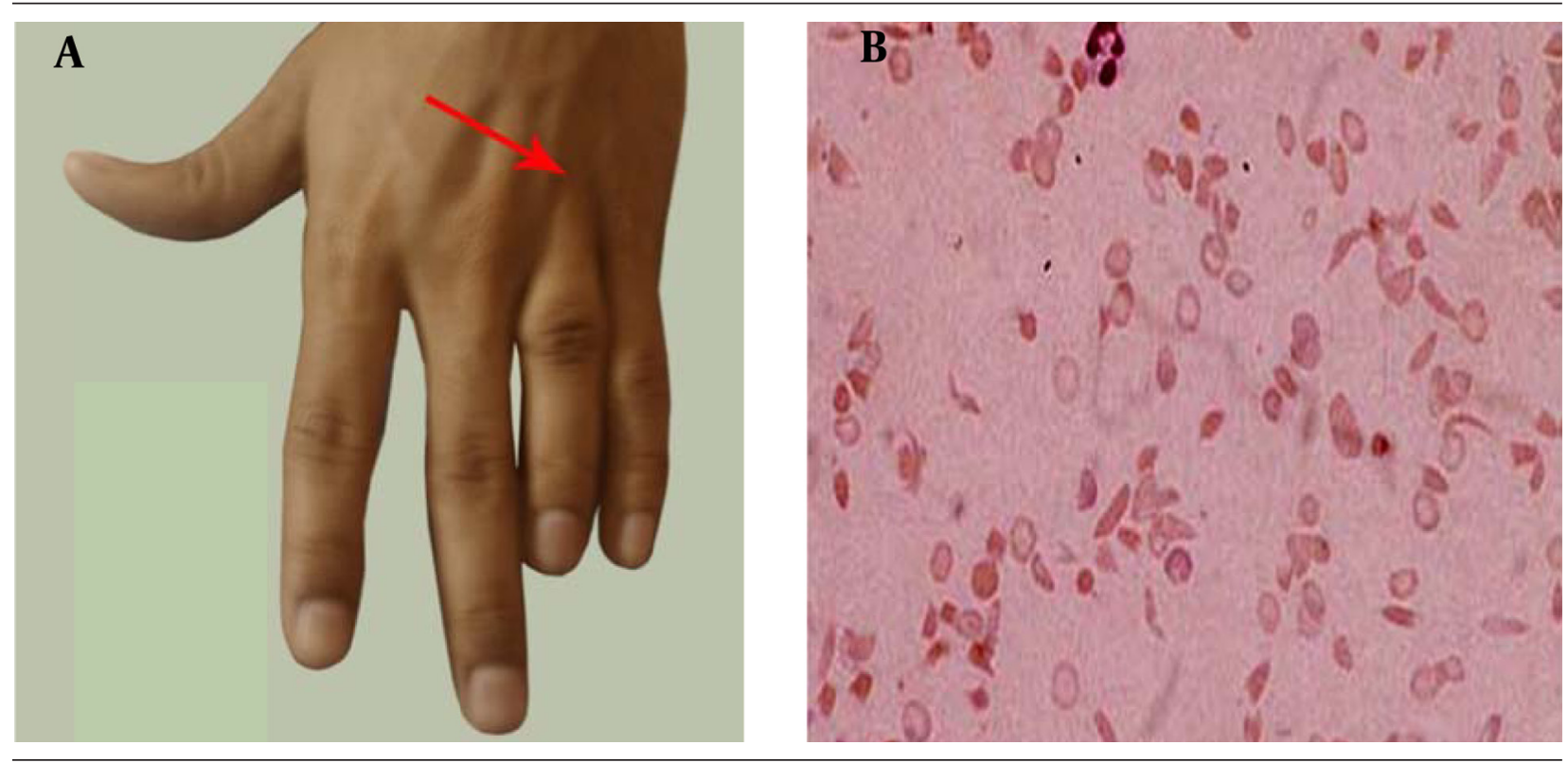

Figure 1. A, Right Short Fourth-Metacarpal Bone; B, Peripheral Blood Smear Showing Sickle cell Bodies

\section{References}

1. Yale SH, Nagib N, Guthrie T. Approach to the vaso-occlusive crisis in adults with sickle cell disease. Am Fam Physician. 2000;61(5):1349-56.
2. Ware MA, Hambleton I, Ochaya I, Serjeant GR. Day-care management of sickle cell painful crisis in Jamaica: a model applicable elsewhere? Br J Haematol.1999;104(1):93-6. 